\title{
Social capital and the utilization of maternal and child health services in India: A multilevel analysis
}

\author{
William T. Story* \\ Carolina Population Center, University of North Carolina at Chapel Hill, Chapel Hill, NC, \\ 27516-2524, USA
}

\section{Abstract}

This study examines the association between social capital and the utilization of antenatal care, professional delivery care, and childhood immunizations using a multilevel analytic sample of 10,739 women who recently gave birth and 7,403 children between one and five years of age in 2,293 communities and 22 state-groups from the 2005 India Human Development Survey.

Exploratory factor analysis was used to create and validate six social capital measures that were used in multilevel logistic regression models to examine whether each form of social capital had an independent, contextual effect on health care use. Results revealed that social capital operated at the community level in association with all three care-seeking behaviors; however, the results differed based on the type of health care utilized. Specifically, components of social capital that led to heterogeneous bridging ties were positively associated with all three types of health care use, whereas components of social capital that led to strong bonding ties were negatively associated with use of preventive care, but positively associated with professional delivery care.

\section{Keywords}

Social capital; maternal and child health; utilization; multilevel analysis; India

\section{Introduction}

Social capital has become one of the most popular sociological concepts to be studied in public health. Although the body of evidence linking social capital to lower levels of mortality, better self-rated health and healthy behaviors continues to grow (Islam et al., 2006; Kim et al., 2008), little is known about the relationship between social capital and health care utilization, especially in low- and middle-income countries. In order to better understand the relationship between social capital and health care use, there has been an effort in the public health literature to dichotomize the various conceptualizations of social capital into "structural" and "cognitive" forms (Bain \& Hicks, 1998). Structural social

(C) 2014 Elsevier Ltd. All rights reserved.

"Corresponding author. Tel.: +19199662578; fax: +19199666638, wstory@unc.edu.

Publisher's Disclaimer: This is a PDF file of an unedited manuscript that has been accepted for publication. As a service to our customers we are providing this early version of the manuscript. The manuscript will undergo copyediting, typesetting, and review of the resulting proof before it is published in its final citable form. Please note that during the production process errors may be discovered which could affect the content, and all legal disclaimers that apply to the journal pertain. 
capital primarily reflects Bourdieu's (1986) conceptualization of social capital as resources available through social networks. This form of social capital tends to be objectively verified by measuring individuals' actions and behaviors. Cognitive social capital aligns more closely with Coleman's (1988) and Putnam's (1993) concepts of social trust, reciprocity, and effective norms. This form of social capital tends be subjectively verified by measuring individuals' attitudes and perceptions. These two forms of social capital should not be seen as mutually exclusive, but as complementary because they assess different aspects of social capital.

While the majority of public health research conceptualizes social capital as structural or cognitive, others make the distinction between "bonding", "bridging", and "linking" social capital (Szreter \& Woolcock, 2004). Bonding capital refers to strong ties to family and friends resulting in a densely knit social network where individuals are alike in terms of their social identity (e.g., age, caste, religion, place of residence). Bridging capital, by contrast, refers to weak ties to acquaintances where there is little social involvement between people who are typically not alike in terms of their social identity (Granovetter, 1983). Linking capital is a form of bridging capital that refers to social ties among people interacting across hierarchical power gradients in society (Szreter \& Woolcock, 2004). Since these three forms of social capital reflect the nature of social ties, they align more closely with the conceptualization of structural social capital.

Potential mechanisms through which social capital affects health care utilization are related to components of structural social capital—such as civic participation, political participation, and social networks — and cognitive social capital—such as social cohesion and collective efficacy (Figure 1). Civic participation, which is often measured by membership in community groups, can affect health care use through formally organized activities that address community issues (Carpiano, 2006) or through the informal provision of instrumental and psychosocial support to overcome barriers to care (Perry et al., 2008). Certain types of group membership can also lead to negative outcomes by establishing strong intragroup ties, or bonding social capital, which leads to conformity to traditional norms and restricts individual freedom to make appropriate health care decisions (Portes, 1998). Political participation has the potential to lead to linking ties with people of influence (Poortinga, 2012), which can give rise to opportunities to influence local health policies or lead to social pressure to comply with existing policies. Social capital can also influence health service utilization through social networks between communities (or community members) and representatives of formal institutions such as health care providers, teachers and government officers. These networks are a form of linking social capital and are important for leveraging resources, ideas, and information, especially for poor communities (Woolcock, 2001).

Social cohesion, a component of cognitive social capital, evokes a sense of mutual trust and solidarity among neighbors. This can lead to the ability of a group to enforce and maintain social norms (i.e., informal social control), which can have a positive or negative impact on health care utilization. If group norms promote the use of health services, health care utilization will increase; if group norms discourage the use of health services, health care utilization will decrease. Collective efficacy can also have positive and negative effects on 
health care use by encouraging individuals to forgo their own self-interest and act in the interest of the group (Coleman, 1988).

In order to elucidate the mechanisms through which social capital affects health care utilization in India, we must first address three important gaps in the existing social capital and health literature: (1) it is unclear whether social capital operates as an individual or collective attribute in relation to health care utilization; (2) few studies empirically differentiate between various components of structural and cognitive social capital; and (3) the majority of studies focus on the positive effects of social capital, ignoring the equally important potential negative aspects of social capital.

First, there is disagreement about whether social capital is an individual or collective attribute. There are many researchers who state that social capital is a collective characteristic that should be measured at the group level (Harpham, 2002; Lochner et al., 1999). Other studies report that social capital operates at the individual level through interpersonal trust and civic participation; however, they acknowledge complex interactions between group-level social capital and individual-level social capital (Poortinga, 2006a; Subramanian et al., 2002). In order to understand how social capital operates as a collective attribute, it is important to consider the size of the geographic area. Studies show that social capital can be better understood at the level of the local community, where it depends on day-to-day interactions between neighbors, compared to the state or country level, where social capital reflects more distal social policies (De Clercq et al., 2012; Eriksson et al., 2011; Hamano et al., 2010; Mohnen et al., 2011).

Second, there is a need to differentiate between various components of cognitive and structural social capital. If different components of social capital are used in a single measure, then it is difficult to assess what specific factors are influencing health outcomes (Carpiano, 2006). In a review of the association between social capital and access to health care, Derose and Varda (2009) found that studies reported a differential effect of various forms of social capital on health service use, which calls into question the practice of combining these different types of variables (i.e., cognitive and structural or bonding and bridging) into summary social capital scales. Moreover, studies that distinguish between various components of social capital rarely validate the measures used, making it difficult to determine which components of social capital are actually being measured.

Third, more attention needs to be placed on the importance of negative aspects of social capital in relation to health outcomes. Portes (1998) describes the negative consequences of social capital that are often overlooked in the current literature on social capital and health. For example, tight-knit communities with strong bonding ties can demand conformity and restrict individual freedom and initiative. In addition, communities with high levels of social cohesion can put pressure on individuals to oppose contemporary ideas and innovative thinking for the sake of solidarity.

This study will address all three gaps in the existing literature on social capital and health by examining: (1) whether social capital is associated with maternal and child health care utilization at the community level, beyond the characteristics of individuals belonging to a 
community; (2) the differential association between various forms of social capital and three different types of health service utilization (antenatal care, professional delivery care, and complete childhood immunization); and (3) the potential negative effects of social capital on health care utilization. Before describing the specific hypotheses about social capital in this context, it is important to understand why social capital is relevant to maternal and child health care use in India.

\section{Maternal and child health care use in India}

India has seen significant progress towards reducing maternal and child mortality in the past half century, but this progress has slowed in recent years despite the availability of costeffective health service interventions (Hazarika, 2012). Studies on the use of maternal and child health services in India have primarily focused on the influence of individual and household characteristics, while largely ignoring the influence of the social environment (Stepheson \& Tsui, 2002). This is an important limitation because the sociocultural context is of particular importance to health service utilization in India due to the substantial differences in health policy and expenditures at the state level as well as the salience of village and neighborhood characteristics at the community level. For example, Sunil and colleagues (2006) reported that the percentage of rural women in India who had "excellent" utilization of maternal health services, including antenatal care and delivery care, varied from $6 \%$ in the state of Uttar Pradesh to $92 \%$ in the state of Kerala. The percentage of children reported to have received all recommended immunizations varied from $27 \%$ in Uttar Pradesh to $91 \%$ in Kerala (Ministry of Health and Family Welfare, 2005). Variations across states in utilization rates are attributable to a combination of factors such as distance, availability and quality of skilled providers, and adequacy of infrastructure (Desai \& Wu, 2010; Navaneetham \& Dharmalingam, 2002; Ministry of Health and Family Welfare, 2005).

Community characteristics have also been shown to have an influence on maternal health care use and immunization coverage in India. Stephenson and Tsui (2002) used a multilevel model to examine the association between the use of maternal and reproductive health services and community factors, such as economic development, the strength of the health infrastructure, the presence of health services, and population size. Although population size was the only community-level predictor variable shown to be associated with antenatal care or professional delivery care, there was still unexplained variation at the community level for both service types. These results suggest that influential unobserved community-level factors were omitted from their models. Similarly, Sunil and colleagues (2006) used a multilevel model to show that the use of maternal health services in India was associated with various programmatic variables measured at the community level, including the presence of women's groups (mahila mandal), visits by health workers during pregnancy, and access to public and private health facilities.

The current study posits that social capital is an important community-level factor omitted from previous studies on the utilization of maternal and child health care in India. There are two primary reasons why community-level social capital has the potential to influence the use of maternal and child health services in India. First, disparities in health service coverage continue to persist throughout India (Hazarika, 2012). Therefore, women who have 
unequal access to health services due to financial constraints may benefit from living in communities with social connections to diverse groups of people. The resources embedded in these social relationships have the potential to help women access the care they need. Second, religious or caste organizations in India may reinforce traditional attitudes about the use of preventive care (Vikram et al., 2012). Therefore, women who live in communities with stronger social ties to religious and caste groups may feel pressure to forgo preventive care. To date, only one known study has examined the association between social capital and health care utilization in India (Vikram et al., 2012).

\section{Study hypotheses}

The study hypotheses are based on the conceptual framework presented in Figure 1, which depicts the potential mechanisms through which social capital affects the use of antenatal care, professional delivery care and childhood immunizations. In addition to the hypotheses mentioned below, this study explores the complex interaction between individual- and community-level components of social capital.

H1: Intergroup bridging ties at the community level are positively associated with all three types of health care utilization due to the enhanced availability of new knowledge and financial resources within the community, which enable health service use.

$H 2$ : Intragroup bonding ties at the community level are negatively associated with all three types of health care utilization due to the reinforcement of traditional norms, which may limit the use of health services.

H3: Social networks at the community level are positively associated with all three types of health care utilization due to the availability of linking ties with people of influence in the community, which enable health service use.

H4: Social cohesion and collective efficacy at the community level are positively associated with urgent health care needs due to individuals acting in the interest of the community to help those in need of health care, and negatively associated with preventive health care utilization due to group norms that discourage the use of these types of health services.

\section{Methods}

\section{Study Population}

This study used the 2005 India Human Development Survey (IHDS), a nationally representative, multi-topic survey of 41,554 households in 2,474 villages or urban neighborhoods across 33 states and union territories of India (Desai et al., 2005). The 2005 IHDS was designed to broaden the understanding of human development across India. Detailed information about data collection procedures, funding, quality assurance, and availability of the data has been previously documented (Desai et al., 2010). Household interviews were conducted with 33,510 ever-married women aged 15-49 and included information about all births between the year 2000 and the interview date. The sample for maternal health service utilization included all women who had given birth in the last five years, which yielded an analytical sample of approximately 11,955 women. Further omitting 
those women with item missing data yielded a final analytic sample of 10,739 women in 2,359 villages or urban neighborhoods. The sample for child health service utilization included the youngest child of the women in the maternal health service utilization sample between the ages of one and five. Complete immunization information without item missing data was available for 7,403 children between the ages of one and five in 2,174 villages or urban neighborhoods.

\section{Response Variables}

The response variables for this study were (1) whether the mother attended four or more antenatal care check-ups during her last pregnancy, (2) whether the mother's last birth was assisted by a skilled health professional (i.e., a doctor, nurse, or auxiliary nurse midwife), and (3) whether the mother's child had received all recommended immunizations by twelve months of age: three doses of DPT (diphtheria-pertussis-tetanus) vaccine, three doses of polio vaccine, one dose of BCG (Bacillus Calmette-Guerin) against tuberculosis, and one dose of measles vaccine. All three response variables were measured as binary outcomes. These three indicators were selected because of their positive association with improved maternal, neonatal, and child health outcomes (Campbell \& Graham, 2006; Jones et al., 2003).

\section{Explanatory Variables}

Social Capital-The primary explanatory variable of interest was social capital.

Consistent with procedures used in previous studies on social capital and health, exploratory factor analysis was used to create composite indicators of theoretically distinct components of social capital (Chuang \& Chuang, 2008; Eriksson et al., 2011; Perry et al., 2008). Appendix 1 provides a detailed description of the exploratory factor analysis methods and results. The six components of social capital identified from factor analysis were separated into structural and cognitive forms. Structural social capital indicators include civic participation, political participation, and social networks. Civic participation was measured by household membership in nine social organizations and divided into two distinct categories: (1) membership in development groups, which represent bridging ties (women's groups; youth clubs, sports groups, reading rooms; trade unions, business or professional groups; self help groups; and credit or savings groups) and (2) membership in any religious, caste, or festival organization, which represent bonding ties. Political participation was measured by two survey items: (1) "Have you or anyone in the household attended a public meeting called by the village panchayat/nagarpalika/ward committee in the last year?" and (2) "Is anyone in the household an official of the village panchayat/nagarpalika/ward committee?" The first item was measured using a yes-no response and the second item was measured using a 3-point scale: nobody close to household is a member; somebody close to household is a member; or someone in household is a member. Social networks were defined by three survey items: (1) "Among your acquaintances and relatives, are there any who are doctors?" (2) "Among your acquaintances and relatives, are there any who are teachers?" and (3) "Among your acquaintances and relatives, are there any who are government officials?" Each item was measured on a 3-point scale: no; yes, live in a different village or neighborhood; or yes, live in the same village or neighborhood. 
Cognitive social capital indicators include social cohesion and collective efficacy. Social cohesion was measured by two survey items: (1) "In this village/neighborhood, do people generally get along with each other or is there some conflict or a lot of conflict?" and (2) "In this village/neighborhood, how much conflict would you say there is among the communities/jatis that live here?" Each item was measured on a 3-point scale: a lot of conflict, some conflict, and not much conflict. Collective efficacy was measured by one survey item: "In some communities, when there is a water supply problem, people bond together to solve the problem. In other communities, people take care of their own families individually. What is your community like?" Respondents had two response options: bond together to solve problem or each family solves individually, where bonding together was coded to represent a greater level of social capital.

A factor score for each component of social capital was calculated for each individual. A community-level factor score was created using the entire sample of 41,554 households, not just the 11,955 women who had given birth in the last five years. The community-level score was calculated by taking the average of the individual social capital scores among all respondents in each respective village or urban neighborhood. The individual- and community-level social capital scores were then standardized to have a mean of zero and a standard deviation of one.

Level 1 Covariates: Individual and Household Characteristics-Other individual and household variables related to maternal and child health care were also included in the regression models (Table 1). These variables were divided into two categories: (1) covariates related to maternal health care utilization, and (2) covariates related to child health care utilization. Demographic and socioeconomic factors that have been shown to be related to maternal health care use in India were divided into individual and household characteristics (Stephenson \& Tsui, 2002; Desai \& Wu, 2010). Individual characteristics included the mother's age, education level, caste, religion, number of children, prior complications during childbirth, and access to antenatal care. Age was self-reported and used as a continuous variable. A quadratic term for age was also included due to the nonlinear relationship between age and both maternal health outcomes. Education level was divided into three distinct categories: no education (reference category), standards 1-9, and standard 10-college graduate. Caste was divided into four commonly used categories: Brahmin (reference category), Other Backward Classes, Scheduled Castes (dalits), and Scheduled Tribes (adivasis), plus a residual "Other" category. Religion was divided into three categories: Hindu (reference category), Muslim, and "Other." The number of children a woman had was used as a continuous variable. The variable for previous complications during pregnancy was binary and coded as 1 if the woman had a miscarriage, abortion, or stillbirth in the last five years. Antenatal care was self-reported and was a binary variable coded as 1 if the woman reported attending four or more antenatal care checkups and 0 otherwise. Use of antenatal care was used as an outcome variable as well; therefore, it was used as a predictor variable only in models of delivery by a skilled health professional.

Household characteristics included the husband's education level and a household asset index. Husband's education level was divided into the same three categories as his wife's education level. A household asset index scale, which includes 30 dichotomous housing and 
consumer goods items, was used to reflect asset ownership and housing quality. The household asset index was used as a continuous variable ranging from 0 to 30 .

Characteristics that have been shown to be related to childhood immunization use in India were divided into child characteristics, mother characteristics, and household characteristics (Vikram et al., 2012). Child characteristics included the child's age and sex. The child's age was reported by the mother and used as a continuous variable. The child's sex was coded as 1 for female and 0 for male. Mother characteristics included her age, education level, caste, and religion; and household characteristics include husband's education level and a household asset index. Each variable for mother and household was measured the same as described above.

Level 2 Covariates: Community Characteristics-In addition to individual- and household-level compositional covariates, community-level contextual covariates were included to ensure that any effects observed at the community level were due to social capital and not other measured factors (Table 1). First, average household asset scores were included by taking the mean score for each rural village or urban neighborhood from the entire sample of 41,554 households. Second, average education level for each village and urban neighborhood was included by taking the mean of the highest level of education attained within each household included in the survey. Third, place of residence was included by dividing communities into three distinct categories: urban; rural areas with good infrastructure (where more than $50 \%$ of households in the village have access to roads and more than $75 \%$ of households have electricity), and rural areas with poor infrastructure (where less than $50 \%$ of households in the village have access to roads or less than $75 \%$ of households have access to electricity).

\section{Analytic strategy}

Multilevel analysis was used to estimate (1) the overall association between communitylevel social capital and health care utilization with adjustment for individual and community characteristics ("fixed effects") and (2) the variation in health care utilization outcomes between communities and states ("random effects"). Seven models were used to specify the best fit for the data. Model 1 is an unconditional means model with only the constant term in the fixed and random parts. This model is useful as a null model that serves as a benchmark with which other models are compared. The intra-class correlation (ICC) is used to examine the proportion of the variance in the outcome that is accounted for by variation between communities (level 2) and states (level 3) (Diez-Roux, 2002). Model 2 is the same as Model 1 with the addition of individual-level covariates to account for compositional differences between communities. Model 3 is the same as Model 2 with the addition of community covariates to account for contextual differences between communities. Model 4 is the same as Model 3 with the addition of individual-level social capital variables to assess the individual effect of social capital on maternal and child health service use after adjusting for compositional factors and contextual factors. Model 5 is the same as Model 4, except community-level social capital variables are used in place of the individual-level social capital variables to assess the contextual effect of social capital on health service use. Model 6 is the same as Model 5 with the individual-level measures of social capital added back into 
the model in order to assess whether community-level social capital is associated with maternal and child health service use, above and beyond individual-level social capital. Model 7 is the same as Model 6 with the addition of cross-level interactions between each community-level social capital variable and its individual-level counterpart for a total of six additional interaction terms. This model assesses whether the effect of community-level social capital on health service utilization differs among individuals with varying levels of social capital (Subramanian, 2002).

\section{Results}

Social capital was associated with all three types of maternal and child health services at the community level, beyond the characteristics of individuals belonging to a community. Three of the six components of community-level social capital were significantly associated with antenatal care use after controlling for potential confounding factors at the individual and community level, individual-level social capital, and cross-level interactions between individual and community social capital (Table 2). Net of the other forms of social capital at the community level, women who lived in communities with higher membership in groups that help form intergroup bridging ties had higher odds of antenatal care use ( $\mathrm{OR}=1.22)$, whereas women who lived in communities with higher membership in groups that help form intragroup bonding ties $(\mathrm{OR}=0.83)$ and women who lived in communities with more collective efficacy $(\mathrm{OR}=0.90)$ had lower odds of antenatal care use.

Three components of community-level social capital were significantly associated with professional delivery care use after controlling for confounding and interaction effects (Table 3). Women who lived in communities with higher membership in groups that help form intragroup bonding ties $(\mathrm{OR}=1.19)$, women who lived in communities with more social networks $(\mathrm{OR}=1.12)$, and women who lived in communities with more collective efficacy $(\mathrm{OR}=1.12)$ had higher odds of professional delivery care use.

Two components of community-level social capital were significantly associated with complete childhood immunization after controlling for confounding and interaction effects (Table 4). Children who lived in communities with higher membership in groups that help form intergroup bridging ties ( $\mathrm{OR}=1.18$ ) had higher odds of complete immunization, whereas children who lived in communities with higher membership in groups that help form intragroup bonding ties had lower odds of complete immunization $(\mathrm{OR}=0.86)$.

The most significant interaction effect was between individual bonding ties and community bonding ties for all three outcomes (Figure 2). Individuals with low levels of intragroup bonding ties benefited from communities with higher levels of intragroup bonding ties. However, for individuals with high levels of bonding ties, the effect was reversed, suggesting that communities with higher levels of bonding ties were not particularly helpful to individuals who were already strongly connected to these types of groups.

The multilevel model was appropriate for the analysis of all three outcomes since greater than $50 \%$ of the variation in each outcome was accounted for by the state and community levels (range: $55 \%$ to $63 \%$ ). After running the final model for each outcome, the 
community-level ICC decreased substantially for all three outcomes (range: $11 \%$ to $37 \%$ ). Although the final model accounted for some of the individual variation in the use of each type of health care, a substantial amount of community-level and state-level variation remained unexplained. Additional specification tests and sensitivity analyses are described in Appendix 2.

\section{Discussion}

The results from this study showed that social capital operated at the community level in association with all three care-seeking behaviors, after adjusting for characteristics of individuals within each community (compositional characteristics), characteristics of communities (contextual characteristics), and state-level variations in health service utilization. These findings are in line with other studies that have found a contextual effect of social capital on other health outcomes, including self-rated health (De Clercq et al., 2012; Eriksson et al., 2011; Mohnen et al., 2011), mental health (De Silva et al., 2007a; Hamano et al., 2010), and health behaviors (Chuang \& Chuang, 2008). This study also showed that individual characteristics were important in explaining health care utilization; however, there was an effect of "place" or "community" that could not be attributed to compositional differences, namely social capital.

These results countered some prior studies that did not find a contextual effect of social capital on health (Han, 2013; Poortinga, 2006a; Subramanian et al., 2002). This may be due to a number of factors, including differences across studies in the geographic size of the higher level unit of analysis. Unlike studies that focused on the national (Poortinga, 2006a) or administrative-area level (Han, 2013), the current study focused on the community level, which was a smaller geographical and social unit. At the level of the state or country, social capital may represent macro-social forces, such as culture or social and economic policies, whereas, at the community level, social capital may reflect more proximate social relationships, networks, norms and values (Lochner et al., 1999).

Across all three health seeking behaviors, the most important components of communitylevel social capital included three components of structural social capital-intergroup bridging ties, intragroup bonding ties, and social networks-and one component of cognitive social capital—collective efficacy. However, the ways in which the different forms of social capital affected health care utilization differed for each type of health service. This evidence supports the notion that social capital is composed of heterogeneous parts and contributes to the call to measure different components of social capital separately because of their differential effects on health and health care use (Derose \& Varda, 2009).

This study supported the first hypothesis by showing that women who lived in communities with more intergroup bridging ties had higher odds of antenatal care use, higher odds of professional delivery care use (though this association was not statistically significant), and were more likely to have their children completely immunized. Bridging social capital has been described as an opportunity for individuals within a community to interact with diverse, heterogeneous groups of people (Islam et al., 2006). This form of social capital may positively influence health care utilization by facilitating access to services and resources 
(Kawachi \& Berkman, 2000), providing a voice to communities that are marginalized from sources of power (Cornish, 2010), or encouraging more contemporary modes of thought and increasing information about modern preventive health services (Vikram et al., 2012).

This study also found evidence to partially support the second hypothesis by showing that women who lived in communities with more intragroup bonding ties had lower odds of antenatal care use and were less likely to have their children completely immunized. In contrast to bridging social capital, it has been suggested that bonding social capital can have a negative effect on health, particularly for poor communities (Islam et al., 2006; Kawachi et al., 2008). In a study by Paek and colleagues (2008), they found that community-level social capital had a negative effect on family planning behaviors in Uganda due to the existing norms and values that discourage the use of family planning methods. If behavioral norms discourage the use of health services, then communities with high levels of bonding social capital may have lower levels of health service utilization. This is particularly relevant in the South Asian context, where the use of preventive maternal health services, such as regular antenatal check-ups, is rarely encouraged because these health services are perceived as existing for curative purposes only (Stephenson \& Tsui, 2002). This belief was also highlighted by Vikram and colleagues (2012) who suggested that membership with religious or caste organizations in India may reinforce traditional attitudes about the use of preventive care and discourage mothers from seeking immunizations for their children.

Contrary to the second hypothesis, the current study found that the effect of bonding social capital on health care utilization was not always negative and involved complex interactions. Specifically, this study showed that women who lived in communities with more intragroup bonding ties had higher odds of using a doctor, nurse, or midwife during delivery. The differential effect of intragroup bonding ties is likely due to differences in the types of health services being utilized. Professional delivery care differs from antenatal care and immunizations because it often requires substantial financial resources, especially in emergent situations. This is supported by the notion that, in addition to controlling deviant behavioral norms, bonding social capital is important for "generating mutual aid and protecting the vulnerable (Islam et al., 2006, p.6).”

This study also supported the third hypothesis that social networks were positively associated with all three types of health services at the community level. However, the association between social networks and health care use was statistically significant for antenatal care use and complete childhood immunization at the individual level and not at the community level. Social networks are important for leveraging relationships with individuals who have power and influence within the community, which provides access to new resources, ideas, and information (Ayé et al., 2002; Woolcock, 2001). New ideas and information about preventive health services that are available through one's social networks appear to operate at the individual level. However, social networks operate at the community level with respect to professional delivery care. This may be due to partnerships formed between health care providers and underserved communities, which can improve access to health care (Derose \& Varda, 2009). 
The final hypothesis, which stated social cohesion and collective efficacy are positively associated with urgent health care needs and negatively associated with preventive health care utilization, was also partially supported. Social cohesion was not significantly associated with any type of health care utilization, whereas collective efficacy was negatively associated with the use of antenatal care and positively associated with the use of professional delivery care. The negative association with antenatal care use suggests that collective efficacy has the potential to reinforce unhealthy behavioral norms through informal social control (Portes, 1998). This association is supported by a study on collective efficacy and smoking behaviors, where higher collective efficacy was associated with more smoking in neighborhoods where smoking norms were permissive (Ahern et al., 2009). Therefore, if the use of antenatal care is not perceived as important among individuals in a community, then women who live in close-knit communities may use less antenatal care. One the other hand, collective efficacy brings a community together to help individuals in need, which has the potential to help women gain access to professional delivery care.

Finally, this study showed significant cross-level interactions between all three types of health care utilization and intragroup bonding ties (Figure 2). Women with low levels of bonding ties who lived in communities with higher levels of bonding ties had higher odds of health care utilization, compared to similar women living in communities with lower levels of bonding ties. This may be due to the mutual aid made available to women who are particularly marginalized and vulnerable in communities with higher levels of bonding ties. By contrast, women with high levels of bonding ties who lived in communities with higher levels of bonding ties had somewhat lower odds of preventive care (antenatal care and immunizations) and no significant difference in the odds of delivery care. This may be due to behavioral norms being shared more efficiently among women who are embedded in dense networks of religious and caste groups compared to women who are excluded from these groups. Cross-level interactions have been reported in previous studies on social capital and health (Poortinga, 2006a; Subramanian et al., 2002), which emphasizes the importance of examining the relationship between individual access to social capital available within the community.

This is the first multilevel study of social capital and health care utilization in India, a country with disparate maternal and child health service utilization rates. The findings of this study, however, must be considered in light of various limitations. First, this study was not designed to infer a causal association due to the retrospective, cross-sectional nature of the data. Since reports about social capital relate to the time of the survey and the maternal and child health care questions relate to a time in the past five years, it is difficult to determine whether aspects of social capital had preceded the birth or immunization of their youngest child. Second, complete case analysis was used, excluding women with item missing data from our sample. Since the women with missing immunization data appear to be systematically different from those without missing immunization data, the results for complete childhood immunization may be biased towards more educated and wealthier women and households. Third, although the multilevel models used in this study were able to explain a substantial proportion of the individual variance in all three outcomes (11\% to $37 \%$ decline in ICC), a significant amount of unexplained variance remained at the community and state level. State-level variation not accounted for in this study may be due 
to health financing and other social and economic policies that affect health care utilization, whereas community-level variation may be due to factors related to shared attitudes and beliefs about health services. Fourth, due to limitations of the data, there was no way to differentiate between male and female participation in the social capital questions. This limits the ability to examine the influence of gender on the relationship between household social capital and health care utilization (an area of potential future research). Fifth, the measurement of each component of social capital was limited by the questions that were used in the survey. For example, intragroup bonding ties and intergroup bridging ties were assessed based on questions related to household membership in a variety of community organizations. Although this is the best approximation of social ties in this survey, it is important to remember the limitations of such measures when interpreting the results.

In conclusion, this study has the potential to make significant contributions to the understanding of the role of social capital in health promotion interventions and development initiatives related to health care utilization in India. First, since social capital was found to primarily operate at the community level in India, investments in social capital can have significant spillover effects (Carroll, 2001). That is, efforts to build social capital will not only affect those who are directly involved, but their family, neighbors and community will indirectly experience the consequences (both positive and negative). Second, of the six forms of social capital explored in this study, building and strengthening bridging and linking ties had the greatest potential to positively impact health care utilization in India. Promoting diverse, heterogeneous networks that include individuals with decisionmaking power, may give communities better access to resources and information, as well as more opportunities to voice their claims and negotiate support. Establishing and expanding these diverse networks would be especially beneficial for disadvantaged households that have few assets and little access to services, thus reducing health care inequities (Carroll, 2001; Wakefield \& Poland, 2005). Third, negative aspects of social capital have the potential to further marginalize disadvantaged populations in India and, therefore, cannot be ignored. Aspects of social capital that reinforce behavioral norms, such as bonding ties and collective efficacy, are not necessarily "bad" for the health of the community. In fact, a positive shift in normative behavior towards the use of necessary preventive care could transform bonding capital into a valuable resource. In this case, careful attention must be paid to addressing the norms about the use of antenatal care and immunizations before building or strengthening bonding ties and collective efficacy in India. Fourth, it is important to remember that each state in India has a distinct social and cultural environment. Therefore, any intervention designed to address social capital should be tailored to the unique environment in which it is to be implemented and should be evaluated to determine its effectiveness. Finally, given the potential for social capital to improve maternal and child health care utilization in India, further research is needed. There is a need for longitudinal studies to examine the causal pathways that underlie the associations between social capital and health care use as well as a need for intervention studies to examine how best to increase or strengthen social capital and whether increasing social capital leads to better health care use. 


\section{Supplementary Material}

Refer to Web version on PubMed Central for supplementary material.

\section{Acknowledgments}

This manuscript was developed as part of the author's dissertation at the University of Michigan School of Public health. During the development of this manuscript, the author received financial support from the University of Michigan Rackham Predoctoral Fellowship. The author is grateful to the Carolina Population Center for training support (T32 HD007168) and for general support (R24 HD050924) during the writing of this manuscript. The author would like to thank Sonalde Desai and Reeve Vanneman of the University of Maryland for providing access to the data from the 2005 India Human Development Survey. The author would also like to extend his gratitude to his dissertation committee for their guidance during the development of this manuscript: Sarah Burgard, Paula Lantz, Renee Anspach, Jane Banaszak-Holl, and Jersey Liang.

\section{References}

Ahern J, Galea S, Hubbard A, Syme SL. Neighborhood smoking norms modify the relation between collective efficacy and smoking behavior. Drug and Alcohol Dependence. 2009; 100:138-145. [PubMed: 19010610]

Ayé M, Champagne F, Contandriopoulos AP. Economic role of solidarity and social capital in accessing modern health care services in the Ivory Coast. Social Science and Medicine. 2002; 55:1929-1946. [PubMed: 12406462]

Bain, K.; Hicks, N. Building social capital and reaching out to excluded groups: The challenge of partnerships Paper presented at CELAM meeting on The Struggle Against Poverty Towards the Turn of the Millennium. Washington; DC: 1998.

Bourdieu, P. The forms of capital. In: Richardson, JG., editor. Handbook of theory and research for the sociology of education. New York: Greenwood Press; 1986. p. 241-258.

Campbell OMR, Graham WJ. Strategies for reducing maternal mortality: getting on with what works. The Lancet. 2006; 368:1284-1299.

Carpiano RM. Towards a neighborhood resource-based theory of social capital for health: Can Bourdieu and sociology help? Social Science and Medicine. 2006; 62:165-175. [PubMed: 15992978]

Carroll, TF. Social Development Papers No 3. Office of Environmental and Social Development, Asian Development Bank; 2001. Social capital, local capacity building and poverty reduction.

Chuang YC, Chuang KY. Gender differences in relationships between social capital and individual smoking and drinking behavior in Taiwan. Social Science and Medicine. 2008; 67:1321-1330. [PubMed: 18667260]

Coleman JS. Social capital in the creation of human capital. American Journal of Sociology. 1988; 94(Suppl):S95-S120.

Cornish F, Shukla A, Banerji R. Persuading, protesting and exchanging favors: Strategies used by Indian sex workers to win local support for their HIV prevention programs. AIDS Care. 2010; 22:1670-1678. [PubMed: 21161773]

De Clercq B, Vyncke V, Hublet A, Elgar FJ, Ravens-Sieberer U, Currie C, Hooghe M, Ieven A, Maes L. Social capital and social inequality in adolescents' health in 601 Flemish communities: A multilevel analysis. Social Science and Medicine. 2012; 74:202-210. [PubMed: 22177752]

De Silva MJ, Huttly SR, Harpham T, Kenward MG. Social capital and mental health: A comparative analysis of four low income countries. Social Science and Medicine. 2007a; 64:5-20. [PubMed: 17045716]

De Silva MJ, Harpham T. Maternal social capital and child nutritional status in four developing countries. Health and Place. 2007b; 13:341-355. [PubMed: 16621665]

Derose K, Varda DM. Social capital and health care access: A systematic review. Medical Care Research and Review. 2009; 66:272-306. [PubMed: 19174538]

Desai S, Wu L. Structured inequalities-Factors associated with spatial disparities in maternity care in India. The Journal of Applied Economic Research. 2010; 4:293-319. 
Desai, S.; Dubey, A.; Joshi, BL.; Sen, M.; Shariff, A.; Vanneman, R. Human development in India: Challenges for a society in transition. New Delhi: Oxford University Press; 2010.

Desai, S.; Vanneman, R. National Council of Applied Economic Research, New Delhi. India Human Development Survey (IHDS). ICPSR22626-v8. Ann Arbor, MI: Inter-university Consortium for Political and Social Research; 2005. Computer file[distributor], 2010-06-29

Diez-Roux AV. A glossary for multilevel analysis. Journal of Epidemiology and Community Health. 2002; 56:588-594. [PubMed: 12118049]

Eriksson M, Ng N, Weinehall L, Emmelin M. The importance of gender and conceptualization for understanding the association between collective social capital and health: A multilevel analysis from northern Sweden. Social Science and Medicine. 2011; 73:264-273. [PubMed: 21689877]

Granovetter M. The strength of weak ties: A network theory revisited. Sociological Theory. 1983; $1: 201-233$.

Hamano T, Fujisawa Y, Ishida Y, Subramanian SV, Kawachi I, Shiwaku K. Social capital and mental health in Japan: A multilevel analysis. PLoS ONE. 2010; 5:e13214. [PubMed: 20949091]

Han S. Compositional and contextual associations of social capital and self-rated health in Seoul, South Korea: A multilevel analysis of longitudinal evidence. Social Science and Medicine. 2013; 80:113-120. [PubMed: 23261256]

Harpham T, Grant E, Thomas E. Measuring social capital within health surveys: key issues. Health Policy and Planning. 2002; 17:106-111. [PubMed: 11861592]

Hazarika I. India at the crossroads of millennium development goals 4 and 5. Asia-Pacific Journal of Public Health. 2012; 24:450-463. [PubMed: 21490106]

Islam MK, Merlo J, Kawachi I, Lindström M, Gerdtham UG. Social capital and health: Does egalitarianism matter? A literature review. International Journal for Equity in Health. 2006; 5:3. [PubMed: 16597324]

Jones G, Steketee RW, Black RE, Bhutta ZA, Morris SS. How many child deaths can we prevent this year? The Lancet. 2003; 362:65-71.

Kawachi, I.; Berkman, L. Social cohesion, social capital, and health. In: Berkman, L.; Kawachi, I., editors. Social Epidemiology. New York, NY: Oxford University Press; 2000. p. 174-190.

Kawachi, I.; Subramanian, SV.; Kim, D. Social capital and health: A decade of progress and beyond. In: Kawachi, I.; Subramanian, SV.; Kim, D., editors. Social Capital and Health. New York, NY: Springer; 2008. p. 1-26.

Kim, D.; Subramanian, SV.; Kawachi, I. Social capital and physical health: A systematic review of the literature. In: Kawachi, I.; Subramanian, SV.; Kim, D., editors. Social Capital and Health. New York, NY: Springer; 2008. p. 139-190.

Lochner K, Kawachi I, Kennedy BP. Social capital: A guide to its measurement. Health and Place. 1999; 5:259-270. [PubMed: 10984580]

Ministry of Health and Family Welfare. Background papers of the National Commission on Macroeconomics and Health: Financing and delivery of health care services in India. New Delhi: Government of India; 2005.

Mohnen SM, Groenewegen PP, Völker B, Flap H. Neighborhood social capital and individual health. Social Science and Medicine. 2011; 72:660-667. [PubMed: 21251743]

Navaneetham K, Dharmalingam A. Utilization of maternal health care services in Southern India. Social Science and Medicine. 2002; 55:1849-1869. [PubMed: 12383469]

Paek HJ, Lee B, Salmon CT, Witte K. The contextual effects of gender norms, communication, and social capital on family planning behaviors in Uganda: A multilevel approach. Health Education and Behavior. 2008; 35:461-477. [PubMed: 17513691]

Perry M, Williams RL, Wallerstein N, Waitzkin H. Social capital and health care experiences among low-income individuals. American Journal of Public Health. 2008; 98:330-336. [PubMed: 18172158]

Poortinga W. Social capital: An individual or collective resource for health? Social Science and Medicine. 2006a; 62:292-302. [PubMed: 16024152]

Poortinga W. Community resilience and health: The role of bonding, bridging, and linking aspects of social capital. Health and Place. 2012; 18:286-295. [PubMed: 22037322] 
Portes A. Social capital: Its origins and applications in modern sociology. Annual Review of Sociology. 1998; 24:1-24.

Putnam RD. The prosperous community: Social capital and public life. The American Prospect. 1993; 38

Sivaram S, Zelaya C, Srikrishnan AK, Latkin C, Go VF, Solomon S, Celentano D. Associations between social capital and HIV stigma in Chennai, India: Considerations for prevention intervention design. AIDS Education and Prevention. 2009; 21:233-250. [PubMed: 19519238]

Stephenson R, Tsui AO. Contextual influences on reproductive health service use in Uttar Pradesh, India. Studies in Family Planning. 2002; 33:309-320. [PubMed: 12561780]

Subramanian SV, Kim DJ, Kawachi I. Social trust and self-rated health in US communities: A multilevel analysis. Journal of Urban Health. 2002; 79:S21-S34. [PubMed: 12473696]

Sunil TS, Rajaram S, Zottarelli LK. Do individual and program factors matter in the utilization of maternal care services in rural India? A theoretical approach. Social Science and Medicine. 2006; 62:1943-1957. [PubMed: 16219406]

Szreter S, Woolcock M. Health by association? Social capital, social theory and the political economy of public health. International Journal of Epidemiology. 2004; 33:650-667. [PubMed: 15282219]

Vikram K, Vanneman R, Desai S. Linkages between maternal education and childhood immunization in India. Social Science and Medicine. 2012; 75:331-339. [PubMed: 22531572]

Wakefield SE, Poland B. Family, friend or foe? Critical reflections on the relevance and role of social capital in health promotion and community development. Social Science and Medicine. 2005; 60:2819-2832. [PubMed: 15820589]

Woolcock M. The place of social capital in understanding social and economic outcomes. Isuma Canadian Journal of Policy Research. 2001; 2:11-17. 


\section{Highlights}

- First multilevel study of social capital and health care utilization in India.

- Social capital has a community-level effect on maternal and child health care use.

- The association between social capital and health care use varies by type of care.

- Intragroup bridging ties were positively associated with all three health services.

- Intergroup bonding ties were negatively associated with use of preventive care. 
Structural Social Capital

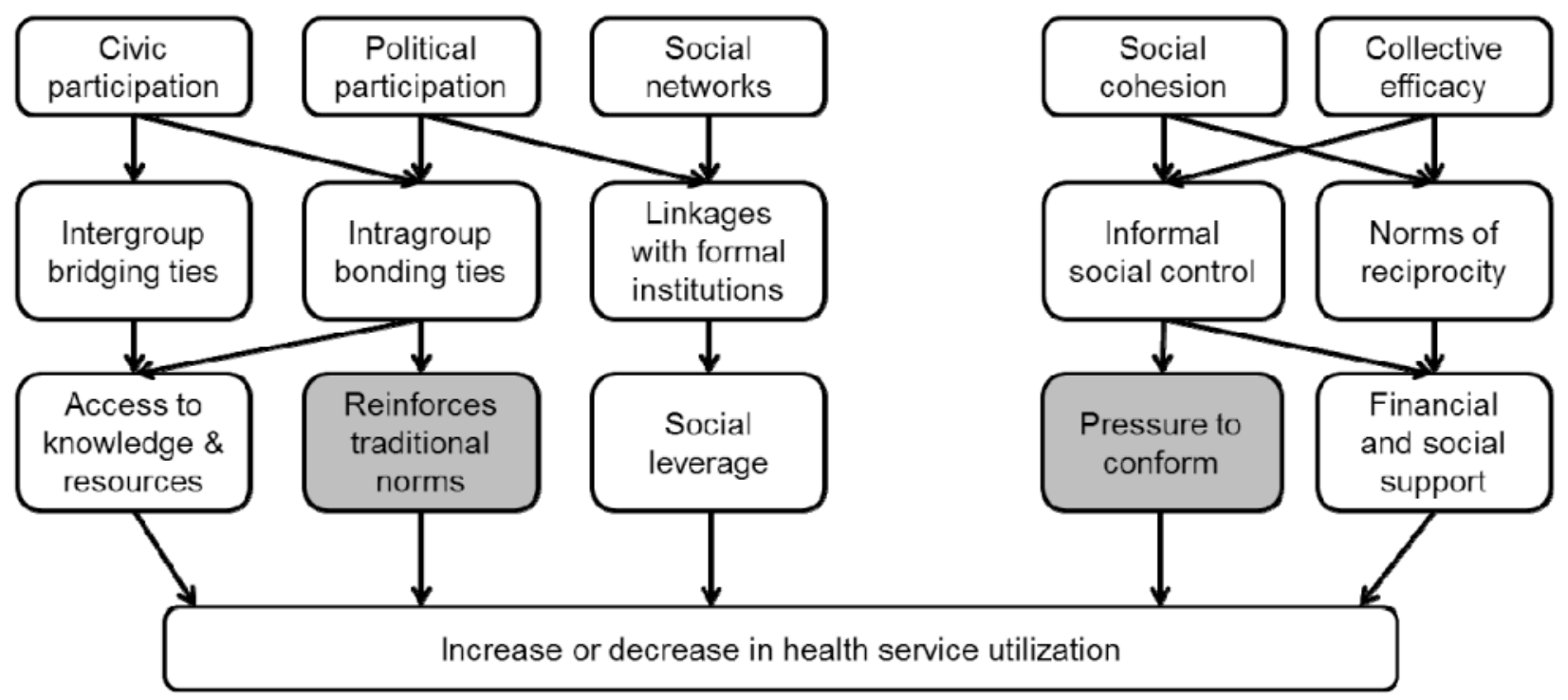

Figure 1.

Conceptual framework for the relationship between social capital and maternal and child health care utilization in India (Grey box $=$ decrease in health service utilization). 

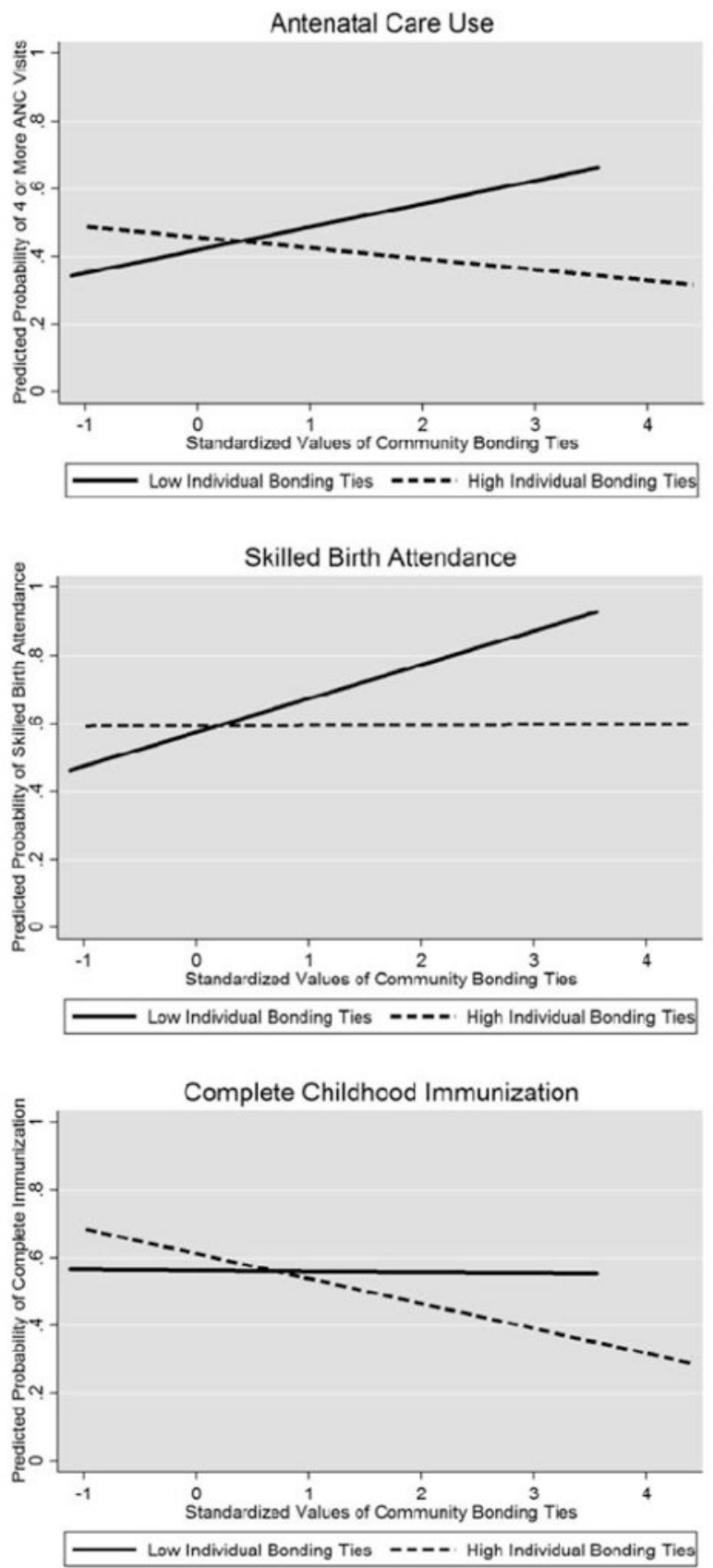

Figure 2.

Cross-level interaction effects of intragroup bonding ties and each form of health service utilization. 
Table 1

Summary statistics for ever-married women age 15-49 and their communities from the India Human Development Survey, 2005

\begin{tabular}{|c|c|c|c|c|}
\hline & $\mathbf{N}$ & Mean (S.D.) & Min. & Max. \\
\hline \multicolumn{5}{|l|}{ Outcome variables } \\
\hline Four or more antenatal care visits & 10,739 & $0.42(0.49)$ & 0 & 1 \\
\hline Skilled birth attendant at delivery & 10,739 & $0.56(0.50)$ & 0 & 1 \\
\hline Complete childhood immunization & 7,403 & $0.57(0.50)$ & 0 & 1 \\
\hline \multicolumn{5}{|c|}{ Individual- and household-level explanatory variables } \\
\hline Parity & 10,739 & $1.41(0.58)$ & 1 & 5 \\
\hline Previous complication & 10,739 & $0.19(0.39)$ & 0 & 1 \\
\hline Child's age & 7,403 & $2.7(1.1)$ & 1 & 5 \\
\hline Female child & 7,403 & $0.46(0.50)$ & 0 & 1 \\
\hline Mother's age & 10,739 & $27.4(5.5)$ & 15 & 49 \\
\hline \multicolumn{5}{|l|}{ Mother's education } \\
\hline None & 10,739 & $0.42(0.49)$ & 0 & 1 \\
\hline $1-9 \mathrm{std}$ & 10,739 & $0.35(0.48)$ & 0 & 1 \\
\hline 10 std-College grad & 10,739 & $0.23(0.42)$ & 0 & 1 \\
\hline \multicolumn{5}{|l|}{ Husband's education } \\
\hline None & 10,739 & $0.22(0.42)$ & 0 & 1 \\
\hline $1-9 \mathrm{std}$ & 10,739 & $0.42(0.49)$ & 0 & 1 \\
\hline 10 std-College grad & 10,739 & $0.36(0.48)$ & 0 & 1 \\
\hline \multicolumn{5}{|l|}{ Caste } \\
\hline Brahmin & 10,739 & $0.05(0.21)$ & 0 & 1 \\
\hline Other Backward Classes & 10,739 & $0.40(0.49)$ & 0 & 1 \\
\hline Scheduled Castes & 10,739 & $0.22(0.41)$ & 0 & 1 \\
\hline Scheduled Tribes & 10,739 & $0.09(0.29)$ & 0 & 1 \\
\hline Other & 10,739 & $0.24(0.43)$ & 0 & 1 \\
\hline \multicolumn{5}{|l|}{ Religion } \\
\hline Hindu & 10,739 & $0.79(0.41)$ & & \\
\hline Muslim & 10,739 & $0.14(0.35)$ & & \\
\hline Other & 10,739 & $0.07(0.25)$ & & \\
\hline Household asset score & 10,739 & $11.5(6.1)$ & 0 & 30 \\
\hline \multicolumn{5}{|l|}{ Social capital } \\
\hline Intergroup bridging ties & 10,739 & $0(1.0)$ & -1.2 & 7.1 \\
\hline Intragroup bonding ties & 10,739 & $0(1.0)$ & -1.2 & 4.7 \\
\hline Political participation & 10,739 & $0(1.0)$ & -1.6 & 4.4 \\
\hline Social networks & 10,739 & $0(1.0)$ & -1.0 & 3.8 \\
\hline Social cohesion & 10,739 & $0(1.0)$ & -3.1 & 1.2 \\
\hline Collective efficacy & 10,739 & $0(1.0)$ & -3.1 & 1.8 \\
\hline \multicolumn{5}{|c|}{ Community-level explanatory variables } \\
\hline Mean household asset score & 2,293 & $11.5(4.8)$ & 2 & 29 \\
\hline
\end{tabular}




\begin{tabular}{lrrrr}
\hline & $\mathbf{N}$ & Mean (S.D.) & Min. & Max. \\
\hline Mean household education level & 2,293 & $7.2(3.0)$ & 0 & 15 \\
Area of residence & & & & \\
$\quad$ Urban & 2,293 & $0.34(0.47)$ & 0 & 1 \\
$\quad$ Rural - High infrastructure & 2,293 & $0.27(0.44)$ & 0 & 1 \\
$\quad$ Rural - Low infrastructure & 2,293 & $0.39(0.49)$ & 0 & 1 \\
Social capital & & & & \\
Intergroup bridging ties & 2,293 & $0(1.0)$ & -1.5 & 6.2 \\
Intragroup bonding ties & 2,293 & $0(1.0)$ & -1.1 & 4.4 \\
Political participation & 2,293 & $0(1.0)$ & -2.1 & 4.7 \\
Social networks & 2,293 & $0(1.0)$ & -1.4 & 5.2 \\
Social cohesion & 2,293 & $0(1.0)$ & -3.7 & 1.5 \\
Collective efficacy & 2,293 & $0(1.0)$ & -3.6 & 2.1 \\
\hline
\end{tabular}




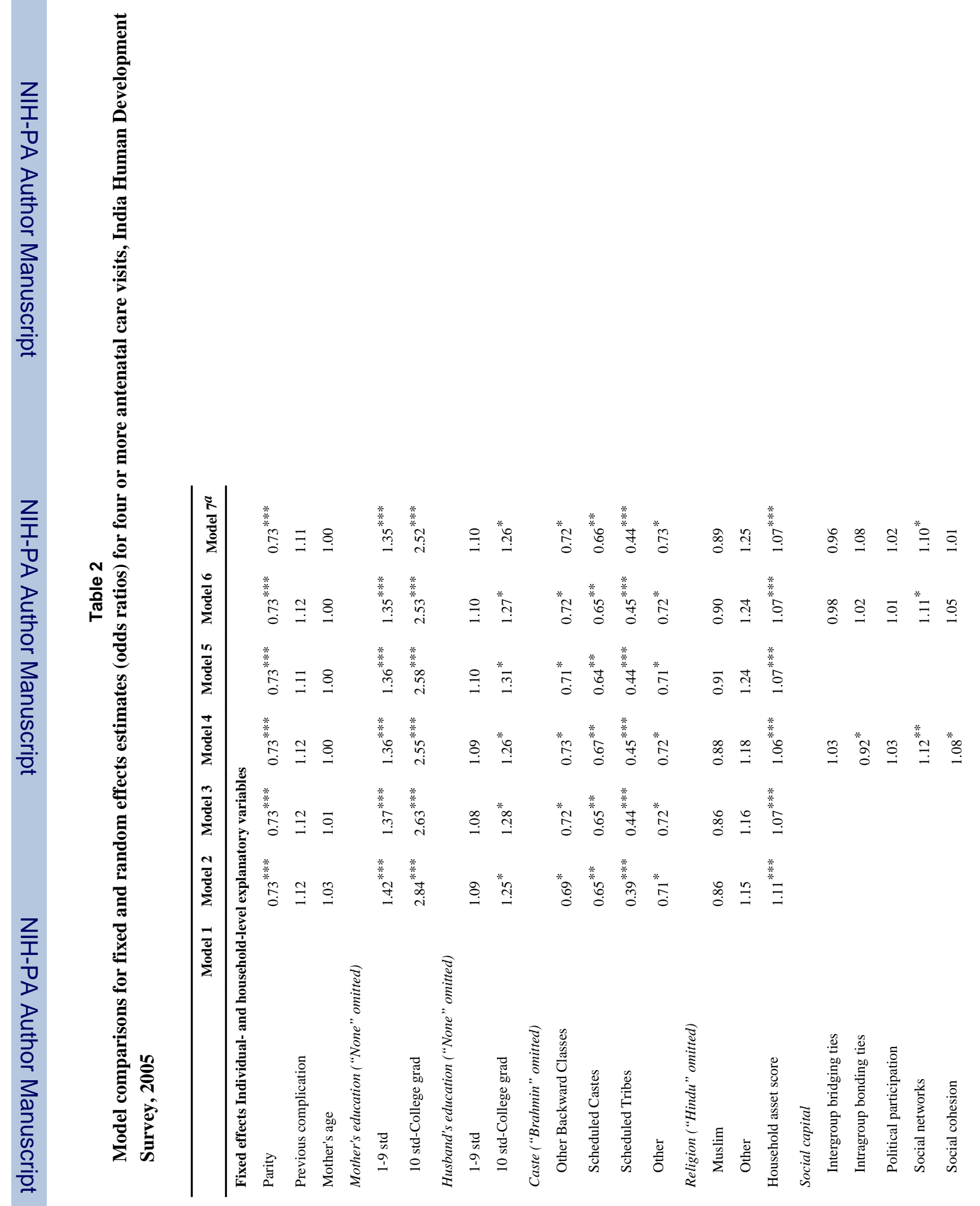




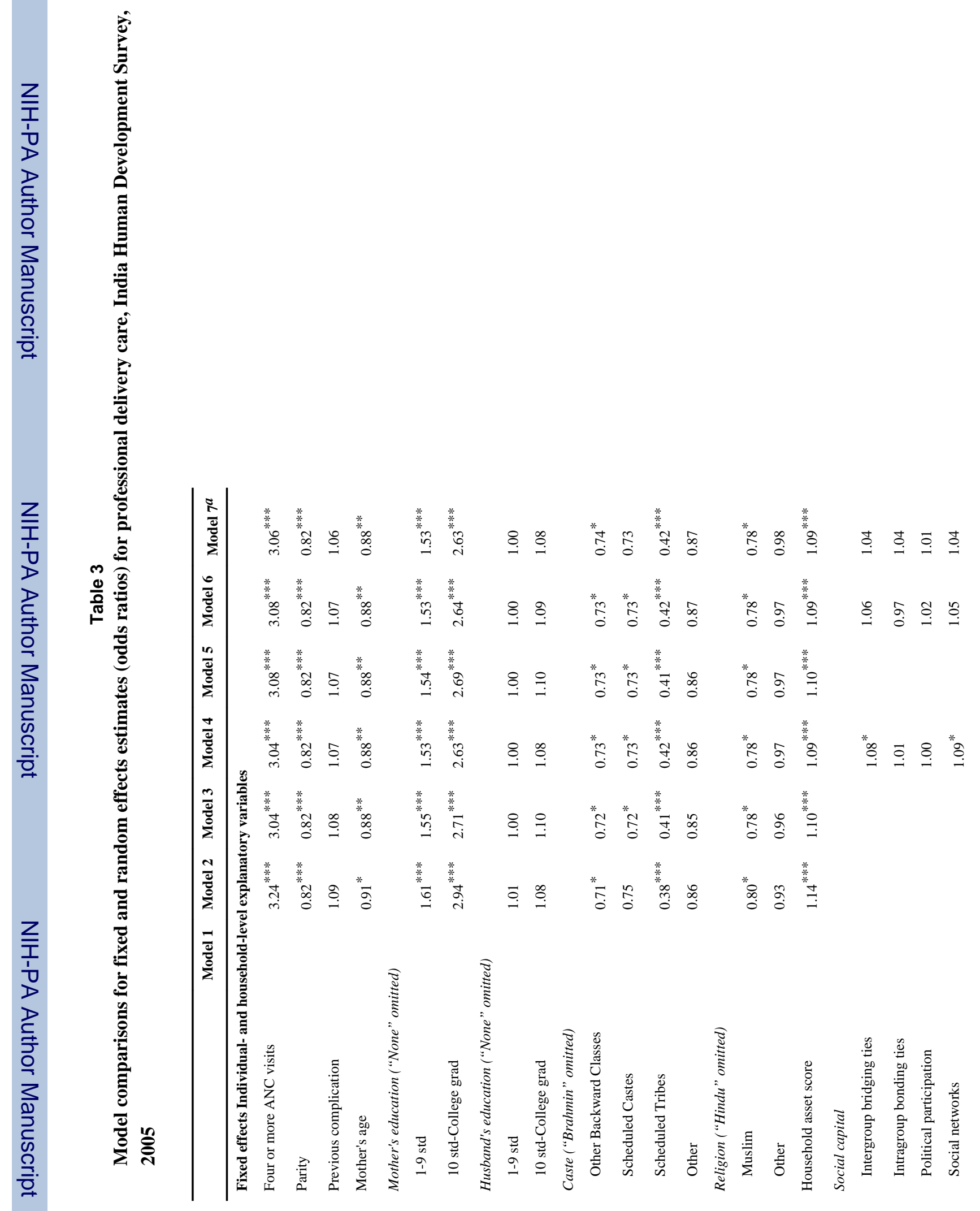




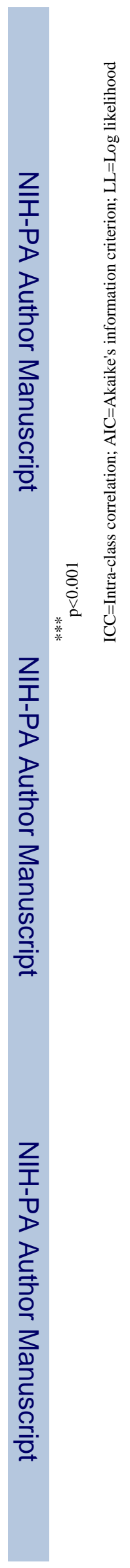




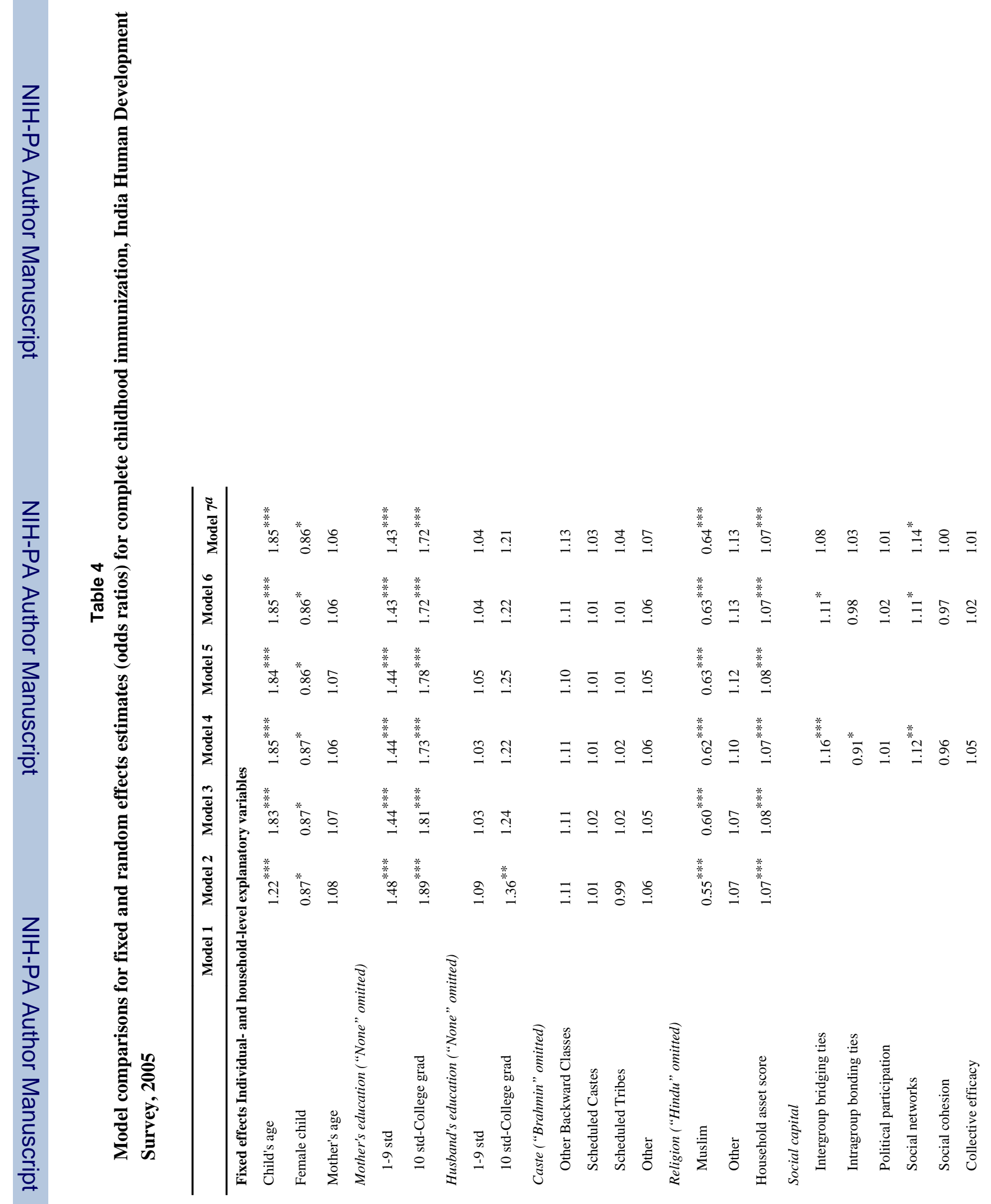


